\title{
ANALISIS KELONGSORAN JALAN POROS SANGALLA-BATUALU DENGAN PROGRAM PLAXIS
}

\author{
Jacob Bokko, ${ }^{1}$ Johan $^{2}$, Parea Rusan R. ${ }^{3}$, Erich Bunga'4 \\ Dosen Teknik Sipil,Fakultas Teknik,UKI Toraja, Kampus II Kakondongan J alan Poros Tallunglipu-Sa'dan \\ Dosen Teknik Sipil,Fakultas Teknik,UKI Toraja, Kampus II Kakondongan J alan Poros Tallunglipu-Sa'dan \\ Dosen Teknik Sipil,Fakultas Teknik,UKI Toraja, Kampus II Kakondongan J alan Poros Tallunglipu-Sa'dan \\ Mahasiswa Teknik Sipil,Fakultas Teknik,UKI Toraja, Kampus II Kakondongan J alan Poros Tallunglipu-Sa'dan
}

\begin{abstract}
ABSTRAK
Longsor merupakan pergerakan tanah dari atas ke bawah pada ketinggian tertentu Telah terjadi kelongsoran di jalan poros sanggalla-batualu. Ada beberapa pilihan terkait penyebab kelongsoran tersebut yaitu akibat adanya beban diatasnya serta rembesan yang melalui tanah.

Maka dari Itu diperlukan analisis kelongsoran di lokasi tersebut. Adapun metode yang digunakan yaitu Metode Elemen Hingga perhitungan dengan menggunakan Software Plaxis( $2 d$ ).

Dari hasil penelitian dan analisis kelongsoran di dapat deformasi setiap section dan faktor keamanan. yang menggambarkan bahwa kondisi lereng tersebut mengalami penurunan. Model deformasi yang di dapatkan dari hasil Plaxis, mempunyai kecenderungan yang sama dengan kondisi deformasi yang terjadi di lapangan sedangkan letak bidang longsor dengan Plaxis, menunjukkan bidang longsor yang menyerupai kondisi di lapangan. kedalaman tiang pancang $7 \mathrm{~m}$ dan jarak tiang pancang $50 \mathrm{~cm}$.
\end{abstract}

Kata kunci : Longsor,Deformasi, Metode Elemen Hingga, Software Plaxis,.

\section{ABSTRACT}

slide is earth move from above downwards on given high. Was become to slide at clears a root sanggalla batualu's axis. There are several option concerning because of that slide which is effect marks sense charges at its settle and seepage that passes through earth .

Therefore of analisis requires to slide at location. There is method even that is utilized which is count Finite Element Methods by use of Software Plaxis( $2 d)$.

Of research result and analysis to slide at can deformation each section and factor of safety. one that figures that condition bevels that experiences decrease. Deformation model at gets from Plaxis's result, having trend that equals happening deformation condition at the site whereas slide area position with Plaxis, pointing out slide area that take after condition at the site. piling depth $7 \mathrm{~m}$ and piling distance 50 $\mathrm{cm}$.

Key word: Slide,Deformation, Finite element methods, Plaxis's software

\section{PENDAHULUAN}

\subsection{Latar Belakang}

Longsor merupakan gejala geologi yang umum terjadi dan mesti akan terjadi dalam rangka mencari keseimbangan alam. Factor utama yang menyebabkan longsor adalah faktor geologi, iklim vegetasi dan penggunaan lahan. Saat memasuki musim hujan secara umum di Indonesia mengalami peningkatan peristiwa longsor akibat ulah manusia seperti penggalian, hilangnya vegetasi, perubahan penggunaan lahan dan lain lain
Kelongsoran yang paling sering di jumpai di lapangan memiliki permukaan yang tidak horizontal (lingkaran) serta dipengaruhi komponen gravitasi. Bilah gaya (beban) yang terjadi karena komponen gravitasi sedemikian besar, sehingga perlawanan geser total pada bidang gelincirnya terlampaui, maka akan terjadi longsoran (hardiyatmo 2002).

Peristiwa yang terjadi dilokasi ini adalah pada musim penghujan, hujan pemicu longsoran adalah hujan yang mempunyai curah tertentu, sehingga air hujan mampu meresap kedalam lereng 
dan mendorong tanah untuk longsor. Secara umum terdapat 2 tipe hujan pemicu longsorsn di Indonesia, yaitu tipe hujan deras dan tipe hujan normal tapi berlangsung lama

\subsection{Perumusan Masalah}

Adapun rumusan masalah yang akan dibahas dalam penelitian ini adalah:

1. Bagaimana model deformasi dalam menganalisis kelongsoran berdasarkan program plaxsis?

2. Bagaimana cara penangulangan kelongsoran dari hasil program plaxis?

\subsection{Tujuan Penulisan}

1. Mendapatkan model deformasi kelongsoran dengan program plaxis.

2. Mengetahui cara penangulangan kelongsoran tersebut.

\section{TINJAUAN PUSTAKA \\ 2.1 Pengertian Tanah}

Tanah didefinisikan sebagai material yang terdiri dari agregat (butiran) mineral-mineral padat yang tidak tersementasi (terikat secara kimia) satu sama lain dari bahan-bahan organic yang telah melapuk (yang berpartikel padat) disertai dengan zat cair dan gas yang mengisi ruang-ruang kosong di antara partikel-partikel padat tersebut
1. Krikil \& Pasir
2. Lanau
3. Lempung

\subsection{Klasifikasi Berdasarkan Tekstur}

Pembagian tekstur berdasarkan kelas tekstur ada 12 ,hal ini sesuai dengan yang dikemukakan oleh, ( Hanafiah, 2005).

1. Pasir (sandy) $\Rightarrow$ Pasir mempunyai ukuran $>2 \mathrm{~mm}$ dan bersifat kasar dan tidak

2. Pasir berlempung (loam sandy) $=>$ Tanah pasir berlempung ini memiliki pasir tidak kuat. Dan juga akan sedikit sekali lengket karena memang

3. Lempung berpasir (Sandy loam) $=>$ Rsa kasar pada tanah lempung berpasir akan terasa agak jelas dan juga akan membentuk bola yang agak keras tetapi akan mudah hancur.

4. Lempung $($ Loam $) \Rightarrow$ Lempung tidak terasa kasar dan juga tidak terasa licin. Dapat membentuk bola yang agak teguh dan dapat sedikit digulung dengan permukaan yang mengkilat. Selain itu, lempung juga dapat melekat.

5. Lempung liat berpasir (Sandy-clay-loam) $=>$ Lempung liat berpasir terasa agak jelas. Dapat membentuk bola agak teguh bila kering dan juga dapat membentuk gulungan jika dipilin dan gulungan akan mudah hancur serta dapat melekat.

6. Lempung liat berdebu (sandy-silt-loam) $=>$ Lempung liat berdebu memiliki rasa licin yang jelas. Dapat membentuk bola teguh dan gulungan yang mengkilat serta dapat melekat.

7. Lempung berliat (clay loam) $\Rightarrow$ Lempung berliat akan terasa agak kasar. Dapat membentuk bola agak teguh bila kering dan membentuk gumpalan bila dipilin tetapi pilinan mudah hancur. Daya lekatnya sedang

8. Lempung berdebu (Silty Loam) $\Rightarrow$ Lempung berdebu akan terasa agak licin. Dapat membentuk bola yang agak teguh dan dapat melekat

9. Debu (Silt) $\Rightarrow$ Debu akan terasa licin sekali. Dapt membentuk bola yang teguh dan dapat sedikit digulung dengan permukaan yang mengkilap serta terasa agak lekat.

10. Liat berpasir (Sandy-clay) $\Rightarrow$ Liat berpasir akan terasa licin tetapi agak kasar. Dapat membentuk bola dalam keadaan kering. Akan sukar untuk dipijit tetapi mudah digulung serta memilliki daya lekat yang tinggi (melekat sekali).

11. Liat berdebu (Silty-clay) $\Rightarrow>$ Liat berdebu akan terasa agak licin. Dapat membentuk bola dalam keadaan kering. Akan sukar dipijit tetapi mudah digulung serta memiliki daya lekat yang tinggi (melekat sekali).

12. Liat (clay) $\Rightarrow>$ Liat akan terasa berat, dapat membentuk bola yang baik. Serta memiliki daya lekat yang tinggi (melekat sekali)

\subsection{Bencana Tanah Longsor}

Longsoran atau gerakan massa erat kaitannya dengan proses-proses yang terjadi secara ilmiah pada suatu bentang alam. Bentang alam merupakan suatu bentukan alam pada permukaan bumi misalnya bukit, perbukitan, gunung, pegunungan, dataran dan cekungan (Dwikorita, 2005). Tanah Longsor merupakan salah satu bencana alam yang sering melanda daerah tropis basah. Kerusakan yang ditimbulkan oleh gerakan massa tidak hanya 
kerusakan secara langsung seperti rusaknya fasilitas umum, lahan pertanian, ataupun adanya korban manusia, akan tetapi juga kerusakan secara tidak langsung yang melumpuhkan kegiatan pembangunan dan aktivitas ekonomi di daerah bencana dan sekitarnya (Hardiyatmo, 2006).

\subsection{Pengertian Tanah Longsor}

Berikut beberapa dari tokoh yang telah dipublikasikan di beberapa pustaka:

1. Skempton dan Hutchinson (1969) tanah longsor atau gerakan tanah didefinisikan sebagai gerakan menuruni lereng oleh massa tanah dan atau batuan penyusun lereng akibat tergangguanya kestabilan tanah atau batuan penyusun lereng tersebut.

2. Varnes (1978) mengusulkan terminologi gerakan lereng yang dianggap lebih tepat untuk mendefinisikan longsoran, yaitu sebagai gerakan material penyusun lereng ke bawah atau keluar lereng di bawah pengaruh gravitasi bumi.

3. Arsyad (1989) mengemukakan bahwa longsor terjadi sebagai akibat meluncurnya suatu volume tanah di atas suatu lapisan agak kedap air yang jenuh air. Dalam hal ini lapisan yang terdiri dari tanah liat atau mengandung kadar tanah liat tinggi dan dapat juga berupa lapisan batuan seperti napal liat (clay shale) setelah jenuh air akan bertindak sebagai peluncur.

4. Cruden (1991) mengatakan longsoran sebagai pergerakan tanah suatu massa batuan, tanah, atau bahan rombakan meterial penyusun lereng (yang merupakan percampuran tanah dan batuan) menuruni lereng.

5. Brook dkk (1991) mengatakan bahwa tanah longsor adalah salah satu bentuk dari gerak massa tanah, batuan dan runtuhan batuan/tanah yang terjadi seketika yang bergerak menuju lereng-lereng bawah yang dikendalikan oleh gaya gravitasi dan meluncur dari atas suatu lapisan kedap yang jenuh air (bidang luncur). Oleh karena itu tanah longsor dapat juga dikatakan sebagai bentuk erosi.
6. Selby (1993) menjelaskan longsoran hanya tepat diterapkan pada proses pergerakan massa yang melalui bidang gelincir yang jelas.

7. Dwikorita (2005) longsor adalah gerakan menuruni atau keluar lereng oleh massa tanah atau batuan penyusun lereng ataupun percampuran keduanya sebagai bahan rombakan, akibat terganggunya kestabilan tanah atau batuan penyusunnya

\subsection{Penyebab Terjadinya Longsor}

Banyak faktor yang mempengaruhi kestabilan lereng yang megakibatkan terjadinya longsoran. Faktor - faktor tersebut semacam kondisi-kondisi geologi dan hidrografi, topografi, iklim dan perubahan cuaca. Pada prinsipnya tanah longsor terjadi bila gaya pendorong pada lereng lebih besar daripada gaya penahan. Gaya penahan umumnya dipengaruhi oleh kekuatan batuan dan kepadatan tanah. Sedangkan gaya pendorong dipengaruhi oleh besarnya sudut lereng, air, beban serta berat jenis tanah batuan. Terdapat beberapa faktor penyebab tanah longsor, diantaranya yaitu:

1. Jenis Tanah

Jenis tanah juga mempengaruhi penyebab terjadinya longsor. Tanah yang mempunyai tekstur renggang, lembut yang sering disebut tanah lempung atau tanah liat dapat menyebabkan longsoran. Apa lagi ditambahan pada saat musin penghujan kemungkinan longsor akan lebih besar pada tanah jenis ini. Hal ini dikarenakan ketebalan tanah tidak lebih dari 2,5 m dengan sudut lereng 22 derajat. Selain itu kontur tanah ini mudah pecah jika udara terlalu panas dan menjadi lembek jika terkena air yang mengakibatkan rentan pergerakan tanah.

2. Curah Hujan

Ancaman tanah longsor biasanya dimulai pada bulan November karena meningkatnya intensitas curah hujan. Musim kering yang panjang akan menyebabkan terjadinya penguapan air di permukaan tanah dalam jumlah besar. Hal itu mengakibatkan munculnya pori-pori atau rongga tanah hingga terjadi retakan dan merekahnya tanah permukaan. Pada saat hujan, air akan 
menyusup ke bagian yang retak. Tanah pun dengan cepat mengembang kembali. Pada awal musim hujan, kandungan air pada tanah menjadi jenuh dalam waktu singkat. Hujan lebat pada awal musim dapat menimbulkan longsor karena melalui tanah yang merekah itulah, air akan masuk dan terakumulasi di bagian dasar lereng, sehingga menimbulkan gerakan lateral. Apabila ada pepohonan di permukaan, pelongsoran dapat dicegah karena air akan diserap oleh tumbuhan. Akar tumbuhan juga berfungsi sebagai pengikat tanah.

3. Kemiringan Lereng

Lereng atau tebing yang terjal akan memperbesar gaya pendorong. Lereng yang terjal terbentuk karena pengikisan air sungai, mata air, air laut, dan angin. Kemiringan lereng dinyatakan dalam derajat atau persen. Kecuraman lereng 100 persen sama dengan kecuraman $45^{\circ}$. Selain memperbesar jumlah aliran permukaan, makin curam lereng juga memperbesar kecepatan aliran permukaan, dengan itu memperbesar energi angkut air.

4.Penggunaan Lahan

Penggunaan lahan (land use) adalah modifikasi yang dilakukan oleh manusia terhadap lingkungan hidup menjadi lingkungan terbangun seperti lapangan, pertanian, dan permukiman. Permukiman yang menutupi lereng dapat mempengaruhi penstabilan yang negatif maupun positif. Sehingga tanaman yang disekitarnya tidak dapat menopang air dan meningkatkan kohesi tanah, atau sebaliknya dapat memperlebar keretakan dalam permukaan baruan dan meningkatkan peresatan.

Penggunaan lahan seperti persawahan, perladangan, dan adanya genangan air di lereng yang terjal. Pada lahan persawahan akarnya kurang kuat untuk mengikat butir tanah dan membuat tanah menjadi lembek dan jenuh dengan air sehingga mudah terjadi longsor. Sedangkan untuk daerah perladangan penyebabnya adalah karena akar pohonnya tidak dapat menembus bidang longsoran yang dalam dan umumnya terjadi di daerah longsoran lama.

5. Getaran

Getaran yang terjadi biasanya diakibatkan oleh gempa bumi, ledakan,getaran mesin, dan getaran lalu lintas kendaraan. Akibat yang ditimbulkannya adalah tanah, badan jalan, lantai, dan dinding rumah menjadi retak.

6. Susut muka air danau atau bendungan

Akibat susutnya muka air yang cepat di danau maka gaya penahan lereng menjadi hilang, dengan sudut kemiringan waduk $220^{\circ}$ mudah terjadi longsoran dan penurunan tanah yang biasanya diikuti oleh retakan.

7. Adanya beban tambahan

Adanya beban tambahan seperti beban bangunan pada lereng, dan kendaraan akan memperbesar gaya pendorong terjadinya longsor, terutama di sekitar tikungan jalan pada daerah lembah. Akibatnya adalah sering terjadinya penurunan tanah dan retakan yang arahnya ke arah lembah.

8. Pengikisan/erosi

Pengikisan banyak dilakukan oleh air sungai ke arah tebing. Selain itu akibat penggundulan hutan di sekitar tikungan sungai, tebing akan menjadi terjal.

9. Adanya material timbunan pada tebing.

Untuk mengembangkan dan memperluas lahan pemukiman umumnya dilakukan pemotongan tebing dan penimbunan lembah. Tanah timbunan pada lembah tersebut belum terpadatkan sempurna seperti tanah asli yang berada di bawahnya. Sehingga apabila hujan akan terjadi penurunan tanah yang kemudian diikuti dengan retakan tanah.

\subsection{Program Plaxis}

PLAXIS mulai dikembangkan sekitar tahun 1987 di Technical University of Delftatas inisiatif dari Dutch Departement of Public Works and Water Management. Plaxis adalah program elemen hingga untuk aplikasi geoteknik di mana digunakan model-model tanah untuk melakukan simulasi terhadap perilaku dari tanah.Program PLAXIS dan model-model tanah didalamnya telah di kembangkan dengan seksama Walaupun pengujian dan validasi telah banyak dilakukan, tetap tidak dapat dijamin bahwa program PLAXIS adalah bebas dari kesalahan. Simulasi permasalahan geoteknik dengan menggunakan metode elemen hingga sendiri telah secara implisit melibatkan kesalahan pemodelan dan kesalahan numerik yang tidak dapat dihindarkan. 
Dalam analisis, data yang dibutuhkan sebagai input-an program Plaxis diantaranya :

1. Nilai parameter tanah yang didapat dari hasil penyelidikan tanah

2. Beban yang ada dilokasi kelongsoran

3. Rembesan air yang meluber dilokasi kelongsoran

Berikut ini fungsi dari bebarapa bagian-bagian utama program masukan Plaxis :

1. Menu Utama : Menu utama memuat seluruh pilihan masukan dan fasilitas operasional dari program masukan.

2. Toolbar Umun : Toolbar ini memuat tomboltombol untuk aktivitas khusus yang berhubungan dengan berkas, pencetakan, zooming (memperbesar atau memperkecil tampilan obyek) ataupun untuk pemilihan obyek.

3. Toolbar Geometri: Toolbar ini memuat tombol-tombol untuk aktivitas khusus yang berhubungan dengan pembuatan model geometri

4. Mistar : Pada sisi kiri dan sisi atas dari bidang gambar terdapat mistar yang menunjukkan koordinat $\mathrm{x}$ dan $\mathrm{y}$ dari model geometri. Mistar ini secara langsung akan menunjukkan dimensi dari geometri.

5. Bidang Gambar : Bidang gambar adalah area gambar dimana model geometri dibuat dan dimodifikasi. Pembuatan dan model geometri umumnya dilakukan dengan menggunakan bantuan mouse.

6. Sumbu : Jika koordinat awal atau salib sumbu berada dalam rentang dimensi yang ditentukan maka pusat sumbu tersebut akan digambarkan sebagai sebuah lingkaran kecil dengan sumbu $x$ dan y diindikasikan oleh anak panah.

7. Masukan Manual : Jika penggambaran dengan menggunakan mouse tidak dapat memberikan tingkat keakurasian atau ketepatan yang diinginkan maka baris Masukan manual dapat digunakan.

8. Indikator Posisi Kursor : Indikator posisi kursor menunjukkan posisi saat ini dari kursor mouse baik dalam satuan fisik (koordinat $\mathrm{x}$ dan $\mathrm{y}$ ) maupun dalam satuan piksel layar tampilan.

\subsection{Penanggulangan Kelongsoran}

Dalam ilmu teknik sipil, jenis tanah dilihat dari besar butiran tanah. Secara garis besar dikedalaman tanah terdapat tanah yang mengandung butiran berdiameter besar seperti pasir/ krikil, batuan dan tanah berbutir halus seperti lanau, lempung. Tanah berbutir halus pada umumnya mempunyai kekuatan geser lebih rendah dari tanah berbutir besar. Tanah berbutir halus yang sering dijumpai adalah lempung atau lanau yang mempunyai tingkat kestabilan rendah, oleh karena itu perlu diadakannya perbaikan tanah.

\subsubsection{Perbaikan Tanah dengan Cara Perkuatan}

a. Pemasangan Vertical Drain

Tanah lempung lunak jenuh adalah tanah dengan rongga kapiler yang sangat kecil sehingga proses konsolidasi saat tanah dibebani memerlukan waktu cukup lama, sehingga untuk mengeluarkan air dari tanah secara cepat adalah dengan mebuat vertical drain pada radius tertentu sehingga air yang terkandung dalam tanah akan termobilisasi keluar melalui vertical drain yang telah terpasang.Vertical drain ini dapat berupa stone column atau menggunakan material fabricated lainnya.Pekerjaan vertical drain ini biasanya dikombinasikan dengan pekerjaan pre-load berupa timbunan tanah, dengan maksud memberikan beban pada tanah sehingga air yang terkandung dalam tanah bisa termobilisasi dengan lebih cepat.

b. Menggunakan Cerucuk Bambu atau Corduroy

Prinsip kerjanya sebelum dilakukan penimbunan terlebih dahulu memasang bantalan baik yang terbuat dari bambu (cerucuk) atau dari kayu gelondongan (corduroy) sehingga saat tanah dihampar tidak bercampur dengan tanah asli dibawahnya dan tanah timbunan tersebut membentuk satu kesatuan yang mengapung diatas tanah aslinya semacam ponton yang mengapung diatas air.Biasanya digunakan kayu bakau, terutama pada tanah lunak. Metode ini sebagai perkuatan yang termurah. Sistem ini lebih sesuai untuk tanah yang selalu basah atau mukaair selalu dipermukaan, misal pada proyek didaerah pantai. Jenis kayu bakau setempat yang kuat dan bulat diameter sekitar 5 sampai $10 \mathrm{~cm}$ dengan panjang 2 samapi 5 meter. Pemancangantiangcerucuksecaramanualbiasanya.

c. Menggunakan Tiang Pancang

Tiang pancang adalah beton prategang yang digunakan untuk pondasi dalam, tiang pancang 
sangat efektif digunakan pada tanah jenis tanah yang lunak

\section{METODOLOGI PENELITIAN}

\subsection{Pengambilan Data}

Data yang digunakan dalam pelaksanaan penelitian ini berupa data primer dan data sekunder.

a. Data primer

Data primer diperoleh dari hasil penelitian lapangan dengan sondir, handbore dan cura hujan .

b. Data sekunder

Kegiatan ini memerlukan data sekunder berupa:

1. Lokasi dan waktu penganbilan data

Pengambilan data pada lokasi penelitan berupa peta lokasi penelitian (peta topografi)

2. Pengambilan data literatur

Pengumpulan data ini diawali dengan pengumpulan informasi yang berhubunga dengan judul, dengan browsing dari internet, standar dan ketentuan pengujian sesuai dengan SNI.

3. Pengambilan dokumentasi

Pengambilan dilakukan dengan mendokumentasikan proses pengambilan data dengan alat uji sondir dan handbor.

\subsection{Pengolahan Data}

Menentukan data data yang di perlukan di program plaxis.Tahap analisa merupakan tahap pengolahan data dari hasil pengumpulan data yang dikelompokkan sesuai dengan tinjauan masalah. Analisa data serta langkah - langkah dalam pengolahan data :

1. Menentukan lokasi terjadinya kelongsoran dan gejala kelongsoran pada ruas jalan poros sanggalla- batualu

2. Pengumpulan data, melalui data primer seperti data skunder pada literatur

pustaka yang mendukung seperti megumpulkan, mengolah , data dan menuliskanya.

3. Kriteria desain sebagai bahan acuan sebagai penangulangan longsor.

4. Perhitungan FK ( faktor keamanan ) longsor pada ruas jalan poros sanggalla- batualu
5.. Analisa penangulangan longsor menggunakan aplikasi Program plaxis v.8.2

6. cara penanggulangan kelongsoran dengan pemadatan tanah.

\section{HASIL DAN PEMBAHASAN}

\subsection{Hasil Pelaksanaan Sondir}

Penyondiran dilakukan dengan menggunakan alat Dutch Cone Penetration Test (DCPT) dengan kapasitas 2,5 ton yang dilengkapi dengan "Adhesion Jacket Cone" Spesifikasi alat DCPT yang digunakan adalah :

- Luas Konus $=10 \mathrm{~cm}^{2}$

- Sudut puncak kerucut konus $=60$ derajat

- Luas mantel (selimut konus) $=150 \mathrm{~cm}^{2}$

- Luas piston penekan $=10 \mathrm{~cm}^{2}$

Penyondiran dilakukan hingga mencapai kedalaman permukaan tanah keras (dihentikan) dengan indikasi yaitu pada saat nilai hambatan konus (cone resistance) $>150 \mathrm{~kg} / \mathrm{cm}^{2}$ atau. telah mencapai kedalaman 20m. Pembacaan local friction (fs) dilakukan pada setiap interval kedalaman 0,2 m.

Pelaksanaan penyelidikan lapangan dilaksanakan pada bulan Maret 2017 . berdasarkan hasil pelaksanaan lapangan diketahui bahwa kedalaman tanah keras dengan indikasi nilai qc $>150 \mathrm{~kg} / \mathrm{cm} 2$ dijumpai pada kedalaman $3,8 \mathrm{~m}$ (referensi titik Sondir 5) hingga 7,6m (referensi titik Sondir 1).

Tabel 4. 1 Tabulasi data hasil pelaksanaan pengujian sondir

\begin{tabular}{|c|c|c|c|c|c|c|}
\hline \multirow{2}{*}{ № } & \multirow[b]{2}{*}{ Kode } & \multicolumn{2}{|c|}{ koordinat } & \multirow{2}{*}{$\begin{array}{c}\text { Kedalaman } \\
(\mathrm{m})\end{array}$} & \multirow{2}{*}{ 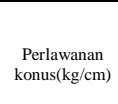 } & \multirow{2}{*}{$\begin{array}{c}\text { Total hambatan } \\
\text { setempat }\end{array}$} \\
\hline & & $\mathrm{x}$ & Y & & & \\
\hline $\begin{array}{l}1 \\
2 \\
3 \\
4 \\
5 \\
5\end{array}$ & $\begin{array}{l}\text { Sondir } 1 \\
\text { Soldir } \\
\text { Sondir } \\
\text { Sondir } \\
\text { Sondir } 5\end{array}$ & $\begin{array}{l}8253877.6 .6 \\
825351.9 \\
8253569.2 \\
85253577.8\end{array}$ & $\begin{array}{l}96553955 \\
99655393 \\
9655509 \\
9655523 \\
96555417\end{array}$ & $\begin{array}{l}7.6 \\
6 \\
5.8 \\
4.8 \\
3.8\end{array}$ & & $\begin{array}{l}316 \\
241 \\
231 \\
185 \\
138\end{array}$ \\
\hline
\end{tabular}

\subsection{Hasil Pelaksanaan Handbore}

Pelaksanaan handbore dilakukan pada empat titik pengujian yang diasumsikan mewakilli model perlapisan tanah pada lokasi pekerjaan, 
berdasarkan hasil pelaksanaan pengujian diketahui bahwa jenis dominasi material permukaan pada lokasi pekerjaan hingga kedalaman $5 \mathrm{~m}$ berupa material lempung dengan ukuran patikel sekunder lanau dan pasir, berwarna coklat tua, konsistensi Lunak-sedang .Tabulasi titik koordinat pelaksanaan handbor dilihat pada Tabel 4.9, sedangkan logbor hasil pelaksanaan pengeboran dapat dilihat pada Gambar 4.7-4.10.

Tabel 4. 9 Koordinat pelaksanaan handbore

\begin{tabular}{|c|l|c|c|c|}
\hline \multirow{2}{*}{ NO } & \multirow{2}{*}{$\begin{array}{c}\text { Titik } \\
\text { Handbor }\end{array}$} & \multicolumn{2}{|c|}{ Xoordinat } & Kedalaman \\
& & & Y & \\
\hline 1 & HB-01 & 825383.39 & 9655406.166 & 5 \\
2 & HB-02 & 825370.08 & 9655395.639 & 2 \\
3 & HB-03 & 825368.66 & 9655399.433 & 4 \\
4 & HB-03 & 825367.92 & 9655416.151 & 2 \\
& & & & \\
& & & & \\
\hline
\end{tabular}

\subsection{Data Pengujian Laboratorium}

Tabel 4. 10 Rekapitulasi hasil pengujian laboratorium

\begin{tabular}{|c|c|c|c|c|c|c|}
\hline \multirow[t]{2}{*}{ NO } & \multirow{2}{*}{ NAMA PENGUJIAN } & \multicolumn{4}{|c|}{ HASIL } & \multirow{2}{*}{ SATUAN } \\
\hline & & HB.01 & HB.02 & HB.03 & HB.04 & \\
\hline 1 & Kadar Air (w) & 34.01 & 31.36 & 25.33 & 18.95 & $\%$ \\
\hline 2 & Berat isi (y) & 1.86 & 1.92 & 1.76 & 1.90 & $\mathrm{Kg} /$ \\
\hline 3 & Berat jenis (Gs) & 2.61 & 2.53 & 2.69 & 2.62 & \\
\hline 4 & $\begin{array}{l}\text { Batas Cair } \\
\text { Batas plastis }\end{array}$ & $\begin{array}{c}53.46 \\
38.99\end{array}$ & $\begin{array}{l}22.63 \\
1030\end{array}$ & $\begin{array}{l}25.56 \\
20.81\end{array}$ & $\begin{array}{l}35.50 \\
21.31\end{array}$ & $\%$ \\
\hline & Indeks Plastis & 14.47 & 12.33 & 4.75 & $\frac{14.19}{86.84}$ & $\%$ \\
\hline 5 & \%Lolos\# No.200 & 74.89 & 71.53 & 65.16 & 86.84 & $\%$ \\
\hline 6 & $\begin{array}{r}\text { Geser Langsung } \\
\text { C } \\
\varnothing\end{array}$ & $\begin{array}{l}0.01 \\
24\end{array}$ & $\begin{array}{l}0.02 \\
27\end{array}$ & $\begin{array}{l}0.01 \\
24\end{array}$ & $\begin{array}{l}0.01 \\
25\end{array}$ & $\mathrm{Kg} /$ \\
\hline
\end{tabular}

\subsection{Analisis kelongsoran dengan program plaxis}

Analisis kelongsoran dianalisis secara numerik dengan bantuan perangkat lunak Plaxis 8.x. Plaxis adalah paket program elemen hingga yang telah dikembangkan secara khusus untuk analisis deformasi dan stabilitas pada pekerjaan geoteknik yang menggunakan Finite Element Method.

Analisa kestabilan jalan dilakukan untuk mengetahui dampak yang terjadi apabila jalan eksisiting di biarkan tanpa adanya tindakan perbaikan. Pada analisis ini teknik pemodelan matematis dengan menggunakan parameter data yaitu :
1) Model geometri penampang melintang pada section 2,3 dan 4 di asumsikan mewakili profile kondisi lapangan

2) Stratigrafi lokasi pekerjaan

3) Data hasil pengujian sondir

4) Data hasil uji laboratorium

5) Beban rencana dengan berat total kedaraan 20 ton

6) Nilai parameter kritis yang digunakan $\mathrm{SF}=1.5$

Model pengujian kelongsoran dibuat pada 3 (tiga) section yang diasumsikan mewakili kondisi lereng pada lokasi penelitian, adapun hasil analisa untuk tiap section yang dimaksud diuraikan sebagai berikut :

\section{1) Section 2}

Jalan eksisiting mengalami deformasi sebesar $4 \mathrm{~cm}$ dengan tipe kerusakan konstruksi jalan berupa crack (rekahan) dan settlement (penurunan) nilai faktor keamanan <1 (Gambar 4.8 ).

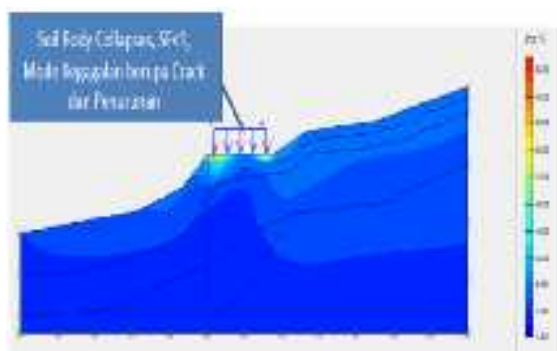

Gambar 4.8 Saat beroperasi beban (deformasi maximum $4 \mathrm{~cm}, \mathrm{SF}<1$, (Collapses)

\section{2) Section 3}

Jalan eksisiting mengalami deformasi sebesar $5 \mathrm{~cm}$ dengan tipe kerusakan konstruksi jalan berupa settlement (penurunan) badan jalan nilai faktor keamanan 1,09 (Gambar 4.9).

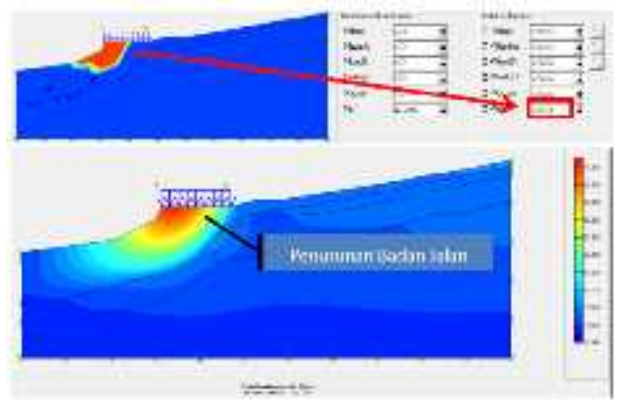

Gambar 4.9 Saat beroperasi beban (deformasi maximum $5 \mathrm{~cm}, \mathrm{SF}=1,09$ ) 


\section{3) Section 4}

Jalan eksisiting mengalami deformasi sebesar $6 \mathrm{~cm}$ dengan tipe kerusakan konstruksi jalan berupa settlement (penurunan) badan jalan dan pemicu longsrosan nilai faktor keamanan 1,13

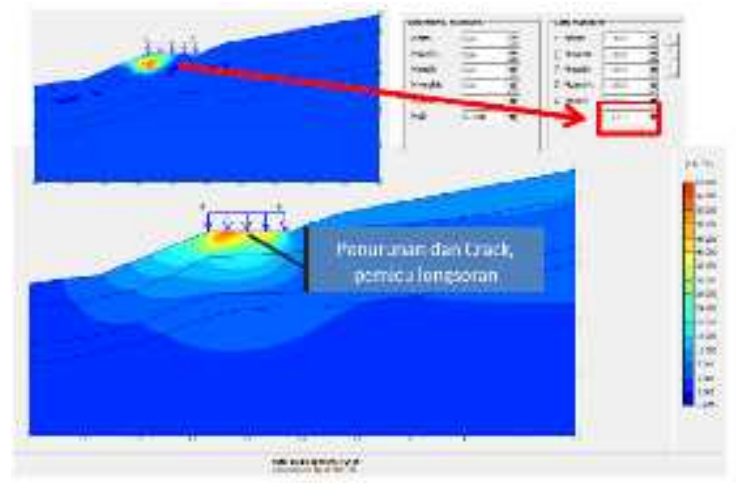

Gambar 4.10 Saat beroperasi beban (deformasi maximum $6 \mathrm{~cm}, \mathrm{SF}=1.13$ )

\subsection{Pondasi Tiang Pancang}

A. Daya Dukung Tiang Pancang

$$
\begin{aligned}
& \text { Qall }=\frac{1}{3} \mathrm{Ap} \mathrm{Qc}+\frac{1}{5} \pi \mathrm{D} J H P \\
& \text { Qall }=\frac{1}{3} \times 1 / 4 \pi \mathrm{D}^{2} \times \mathrm{Qc}+\frac{1}{5} \pi \mathrm{D} J H P \\
& \begin{array}{rl}
\text { Qall } & =\frac{1}{3} \times 1 / 43,14 \quad 20^{2} \times 160+\frac{1}{5} \\
3,1420 & 316 \\
& =\frac{1}{3} \times 706,5 \times 160+\frac{1}{5} 3,1430 \\
316 & \\
& =\frac{1}{3} \times 113.040+\frac{1}{5} 29.767,2 \\
& =37.68+5.953,44 \\
& =43.633,44 \text { ton }
\end{array}
\end{aligned}
$$

a. Jarak Tiang Pancang

jarak tiang pancang( $S$ ) adalah $\varnothing$ tiang +30

$\mathrm{cm}$

$$
\begin{aligned}
& S=20+30 \\
& S=50 \mathrm{~cm}
\end{aligned}
$$

dari hasil penelitian tersebut dan dari hasil uji sondir di dapat kedalaman tanah keras kedalaman titik sondir S-1 (7m ),S-2 (6m),S-3 (5.80m), S-4 $(4.80 \mathrm{~m}), \mathrm{S}-5 \quad(3.80 \mathrm{~m})$, jadi kedalaman tiang pancang adalah $7 \mathrm{~m}$ (kedalaman maksimum dari semua titik sondir) dan jarak tiang pancang adalah $50 \mathrm{~cm}$

\section{KESIMPULAN DAN SARAN \\ 5.1 KESIMPULAN}

1. Model deformasi yang di dapatkan dari hasil Plaxis mengalalami penurunan . Section 1 mengalami penurunan sebesar $4 \mathrm{~cm}$, section 2 mengalami penurunan sebesar $5 \mathrm{~cm}$ dan section 3 mengalami penurunan sebesar $6 \mathrm{~cm}$.

2. cara penanggulangan kelongsoran dari hasil program plaxis dengan menggunakan tiang pancang,jarak tiang pancang $50 \mathrm{~cm}$ dan kedalaman $7 \mathrm{~m}$

\subsection{SARAN}

1. Di perlukan penyelidikan tanah kompre hensif, pengukuran muka air tanah yang akurat dan interpretasi penampang profil tanah yang mendekati kondisi lereng untuk mendapatkan hasil analisis yang baik.

2. Untuk penelitian lanjut di sarankan untuk membandingkan analisa secara manual dengan analisa mengunakan program

\section{DAFTAR PUSTAKA}

Darnawijaya I., 1980 ; Klasifikasi Tanah, IPB Bogor.

Dinas Energi Dan Sumber Daya Mineral Propinsi Jawa Timur, 2003, Identifikasi Kawasan Rawan Gerakan Tanah Dan Longsor Di Jawa Timur Khususnya Di Obyek Wisata Dan Pemukiman, Tidak Dipublikasikan, Surabaya.

Hardiyatmo, Hary, C. 1992. Mekanika Tanah 1. Gajahmada, Yogyakarta.

Hardiyatmo, Hary, C.2010.Analisis dan Perancangan Fondasi bagian I. Gajahmada, Yogyakarta.

Hardiyatmo, Hary, C.2010.Analisis dan Perancangan Fondasi bagian II. Gajahmada, Yogyakarta.

Karnawati, D. 2000, The Importance of Low Intensity Rainfall on Landslide Occurrence, Forum Teknik, Vol 24 / No.1, Univ. Gadjah Mada, Yogyakarta 
Karnawati, D., 1996, Mecahanism of Raininduced Landslides in Java, Media Teknik No.3 th XVIII Nov, 1996

Karnawati, D., 2004, Bencana Gerakan Massa Tanah/Batuan di Indonesia, Evaluasi dan Rekomendasi, hal. 9-38, Permasalahan, Kebijakan dan Penanggulanagan Bencana Tanah Longsor di Indonesia, P3TPSLK-BPPT dan HSF, Jakarta

Plaxis 2D Version, 1998, Manual Book, A.A.

Balkema, P.O. Box 1675, 3000 BR Rotterdam, Netherlands.

Suryolelono, K.B., 2000, Geosintetik Geoteknik, Nafiri, Yogyakarta Widodo, A., 2002,

Resistivitas pasir di Laboratorium, Prosiding IAGI ke 32. Surabaya 